\title{
Contributions of Neuroscience to a New Empathy Epistemology: Implications for Developmental Training
}

\author{
Diane S. VanCleave
}

\begin{abstract}
The difficulty in comprehending the epistemology of empathy lies in shifting paradigms which have resulted in empathy being viewed as vague and elusive. Such elusive understanding of empathy has confused research, practice, and advancement of therapeutic principles. Empathy is the core of all social and intellectual transformation. Humankind is biologically programmed to use empathy for survival, health, and wellbeing. Pursuing and understanding empathy frees human capacity for wisdom. Studying the epistemology of empathy is operationally and scientifically relevant in the synthesis of an empathic practice theory. Clear epistemic definition and neuroscience provide the foundation for an expanding discovery of rational frameworks for a clinician's empathic training and teaching. A clinician's empathic ability requires competency in reflective, global, affective, cognitive, and interpersonal perspective-taking. Once understood, renewed curriculum for teaching and training are recommended that would produce more finite outcomes. Epistemic review culminates in empathy skills training over the course of curricula at the undergraduate (BSW) and graduate (MSW) levels.
\end{abstract}

Keywords: Empathy; neuroscience; teaching; perspective-taking

Some therapists see empathy in human relationships as elemental to survival, to relationship, to physiological well-being, and to therapeutic success (Norcross, 2011). If empathy is so necessary to human survival, why the apparent lack of urgency in understanding, analyzing, and developing effective training models? This article provides an epistemic review of literature on empathy to argue for better training.

An effective study of empathy should first include an examination of viable empathy definitions which are congruent with contemporary social work practice philosophies. Current discoveries in neuroscience have lent clinical legitimacy, supporting empathy as a powerful tool within social work practice. Neuroscience, Rogerian philosophy, therapeutic practice, and humanism provide epistemic proofs of empathy (e.g., Carkhuff, 1984; Davis, 1980; Decety, 2010; DeCruz, Boudry, DeSmedt, \& Blancke, 2011; Gerdes \& Segal, 2011; Rogers, 1975, 2003). The plan for this analysis is to consider what is already known about empathy and its place in therapeutic skill development.

\section{Contradictions}

Early empathy studies have diverged into debates over nature versus nurture, cognition versus affect, and interpersonal versus intrapersonal dualities (Chambers \& Davis, 2012; Dvash \& Shamay-Tsoory, 2014). Advances in neuroscience, research findings, and reexamination of historical touchpoints lead to a more contemporary and broader understanding of empathy (Bal \& Veltkamp, 2013; Rogers, 1975). Empathy has a primary

Diane S. VanCleave is an Assistant Professor in the Social Work Department at Indiana State University, Terre Haute, IN 47809 .

Copyright @ 2016 Author Vol. 17 No. 2 (Fall 2016), 369-389, DOI:10.18060/21087 
role in brain function and thus survival, involving extensive interplay between affective and cognitive regions of the brain.

\section{Historical Touchpoints}

Carl Rogers has been the social work standard-bearer for empathy application. Rogers (1951/2003) offered early philosophies on empathy as a part of humanism that supported growth and transformation through genuine, positive regard. At the end of his professional career Rogers (1975) attempted to articulate a more finite definition of empathy that conveyed empathy's precise process of substance and meaning. In 1975, Rogers clarified empathy as an action of the therapist's voluntarily surrendering into another's perceptual world with the sensitivity to experience emotions of the other, moment by moment, without succumbing to the emotion or judgment of the other. During this action process, the therapist is able to move the client from a discovery of meaning to a fuller experience (Gendlin, 1962; Gerdes, Segal, \& Lietz, 2010; Rogers, 1975). Interestingly, Rogers saw the process of this empathy interaction as a growth experience, not only for the client, but for the social work clinician as well (Gerdes \& Segal, 2011).

\section{Nature Versus Nurture}

If nature and nurture work in concert, innate precipitators are likely to be present to activate the nurturing desire for an empathic response (Gerdes \& Segal, 2011). Motivation, drive, creativity, imagination, and reflective/reflexive processes act to prod the subject to move into empathy and would be activated in certain activity (Erez \& Isen, 2002; Gerdes \& Segal, 2011; Kasapi \& Mihiotis, 2014; Lachmann, 2008; Yaniv, 2012). Affirming the nature/nurture connection, studies have shown significance for increased perspectivetaking and empathic concern (altruistic compassion) when watching films (Gerdes, Segal, Jackson, \& Mullins, 2011; Martin et al., 2015). Additionally, reading fiction has resulted in significant transformation in empathic fantasy development (Bal \& Veltkamp, 2013). Empathy, as more than simply promoting compassion, aids in increasing intelligence (Dearing \& Steadman, 2009; Gardner, 2006). Gardner (2006) connected empathic intelligence/wisdom to interpersonal, intrapersonal, logic, kinetic, linguistic, spatial, and naturalistic experience. As an example, Gardner (2006) identified musical intelligence as a valuable empathy outcome.

\section{Operational Empathy}

Empathy has shown that it can be operationalized, making it research testable. Davis (1980) divided empathy into component parts: perspective-taking, empathic concern, empathic distress, and fantasy (Davis \& Hayes, 2011). The Davis Interpersonal Reactivity Index (IRI) has become one standard measure that can evaluate these empathy components (Chambers \& Davis, 2012; Davis, 1980). Empathic films and discussion have been instruments of measure for empathic concern and perspective-taking. 


\section{Intrinsic Empathy}

Decety (2010) defined empathy intrinsically: internalizing observed feelings of others (mirroring), imagining another's feelings, and recognizing separate feelings of the self and of another. Rogers (1975) identified this as the ability to hold one's own emotions while experiencing the emotions of the other. Miehls and Moffatt (2000), both practicing social workers, challenged clinicians not to withhold their affective sharing from the client. According to Miehls and Moffatt, unrestrained interactions could bring a new transparency to session work and elevate treatment outcomes. In open exchange, social work students must learn the nuanced balance between compassionate sympathy and immobilizing empathy (Nilsson, 2014). Clinicians need to be in touch with their own defenses, resistance, and flaws.

\section{The New Paradigm of Empathy}

Over the years, numerous social workers have developed a definition of empathy to fit their own experience. These multi-layers of contribution show the difficulty in forwarding a workable definition. Empathy is the central core of social work and cannot be ignored. The nature, belief, rationale, scope, and justification in an epistemic review of empathy affirm the power of empathy (Juliusdottir, 2006).

A working definition of empathy has emerged from this discussion. Rogers' (1975) definition of empathy affixes the process of substance and meaning, with the social worker voluntarily surrendering into another's perceptual world. Empathy types include cognition, affect, and interpersonal exchange. Davis (1980) and Decety (2010) identified empathy components as perspective-taking, empathic concern, distress, and fantasy — with Decety's inclusion of the intrinsic qualities. Practice/skill behaviors of use to social work are compassion empathy, empathy-responding, intellectual empathy, and empathy discrimination (Dearing \& Steadman, 2009; Linker, 2011; VanCleave, 2007). Capacities associated with high levels of empathy are intuition, openness, insight, motivation, creativity, and interpersonal skills (Buckman et al., 2011; Smith, 2012).

\section{The Neuroscience}

LeDoux (2002) has contended that biology has now affirmed empathy. As the human species, we had to be able to use our neural circuitry (our intellect and our affect) in concert to create social and protective groups which would guarantee individual and group survival. If our thoughts and feelings did not work in tandem, then mother-child bonds would not have been formed. Infants would have been exposed to certain death. We would not have been able to draw together in groups and communities to survive threats and dangers. Nurturing, care, innovation, translations of joy, conveyed history, and resourcefulness would have been nonexistent, and the human species would have faded from the earth. A well-orchestrated blending of feeling and thought exists within cognitive systems that have evolutionary threads connecting to primal survival.

To achieve a complex coexistence between the cognitive and the affective, the brain developed an affective system called the limbic system (Decety \& Svetlova, 2012). The limbic system functions as a connection between the primitive portion of the brain and the 
higher-ordered neocortex. There is an interplay between brain systems dedicated to empathy. The limbic system (affect) projects to the anterior cingulate cortex (cognitive) to assist in regulation and decision-making from the emotional data (Decety \& Svetlova, 2012).

Neuroscience has provided proof that the intellect/affect connection exists. Specific brain structures are responsible for sensory perception of facial stimuli and language processing, directly impacting empathy (Gu, Hof, Friston, \& Fan, 2013; Marcum, 2013). Brain imaging has identified self-correcting centers for empathy assessment and accuracy (Shamay-Tsoory, 2015). Affective brain systems stimulate corresponding cognitive processes. The density of gray matter regulates levels of cognitive and affective empathy (Eres, Decety, Louis, \& Molenberghs, 2015). Greater density in one region enhances cognitive empathy; greater density in another region of the gyrus affects perspective-taking (Chambers \& Davis, 2012). Eres and colleagues (2015) surmised that density composition (in either the affective or cognitive regions) was altered (made more or less dense) with empathy practice.

\section{Empathy's Neuroscience Connection to Intellect}

The social world has required a willingness and an ability to share cognitive experience within an affective state (Gerdes \& Segal, 2011; Ong, Zaki, \& Goodman, 2015). The ability to understand the world rests in integrating and sharing in the other's emotional states (Decety, 2010). A full command of empathy intelligence is then elemental for interactive relationship with another (Gardner, 2006). From an evolutionary perspective, success and survival in full participation with the world is necessary for social protection, effective social integration, and social bonding (Decety \& Svetlova, 2012; Mutschler, Reinbold, Wankerl, Seifritz, \& Ball, 2013).

Without access to empathy, there are no intellectual resources to draw upon for basic decision-making, calculating others' responses, and communication with another. Visceral cues from emotions have affirmed decision-making (Lehrer, 2010). The recent discovery of mirror neurons as visceral cues has explained the transfer of skills from generation to generation. In addition, while watching another feel pain, the mirror neurons fire, creating a sense of that feeling of pain (Lehrer, 2010). Mirror neurons have also explained a heightened identification with skill-building as one observes another completing tasks (Martin et al., 2015). While equipped with mirror neurons from birth, modeling is required from parental figures to ingrain prosocial behaviors that occur in the infant at about 14 months of age (Aksan \& Kochanska, 2005). It takes modeling or nurturance to bring prosocial behaviors forward.

\section{Neurochemical Link}

The role of well-placed neurotransmitters is elemental in the development of relationships. Bonds and relationships are established and maintained with the help of enkeuphalin (encephalin) and dopamine (Decety \& Svetlova, 2012). These reward pathways additionally influence affiliative and bonding behaviors. Social contacts mediated by these opioids are the glue of social interaction (Decety \& Svetlova, 2012). The 
effect of initiating empathy-responding activates prosocial behavior, like the hormonallyinduced desire toward altruism. In therapeutic practice, this combination of hormones may drive clinicians to greater competency with their clients.

For the clinical social worker, transmitting empathy in session releases endorphinsgiving the social worker pleasure (Grant, 2014; Loyola, 2016; Pavey, Greitemeyer, \& Sparks, 2012). From the perspective of a helpful professional, both client and social worker are nurtured and transformed as the result of interpersonal processes (Cialdini, Schaller, Houlihan, \& Beaman, 1991; Welp \& Brown, 2013). Therefore, interpersonal exchange, for both client and therapist, fosters resilience, trust, healing, personal growth, creativity, and learning from the nourishment of therapeutic exchange (Morelli, Leiberman, \& Zaki, 2015). The social worker is genuinely using self as a conduit in transforming conflict, in collaborative action, with the expectation of positive individual change.

Proof of the importance of these transmitters is exemplified by the biochemical link of oxytocin to compassion (Decety \& Svetlova, 2012). Oxytocin has many therapeutic purposes, such as increased bonding when identifying with someone in pain (Abu-Akel, Palgi, Klein, Decety, \& Shamay-Tsoory, 2014). Oxytocin and dopamine can act together where bonding creates a preference for social interaction with another. Oxytocin may be a trust hormone that is the foundation for empathy (Barraza \& Zak, 2009). This trust also implies empathy-responding that builds into addictive patterns and a subsequent greater need for bonding and deeper interpersonal connection between therapist and client.

\section{Developmental Empathy}

The biologic legitimacy of empathy and morality have a presence in the developmental process of the human experience, even from birth. That interpersonal practice begins in infancy, with the discovery that crying induces holding, hugging, and an expression of bonding with the caregiver (Spinrad \& Stifter, 2006). However, social functioning of empathy as a cognitive function presents beyond the age of 10 years, when the child is developmentally able to initiate interpersonal exchange (Decety, 2010). Empathy development typically grows with modeled empathy, inducing a greater desire to react in a manner that reinforces an empathy response from others.

When developmental empathy modeling and bonding are not present in childhood, creative and empathic induction can occur in a psychodramatic session (Yaniv, 2012). A psychodramatic concept, like role reversal, can be introduced as suspension of disbelief or a role-play experience (Holland, 2003). In this state, what was not integrated into childhood experience may be integrated into the adult mind at the time of the psychodrama session. The creativity of more complete role-taking (such as in a psychodramatic experience) may enhance the ability to more fully receive empathic responses.

\section{Empathy Responding}

The use of the reflective and reflexive self in therapy has provided more meaningful opportunities for therapeutic advancement and growth (Hieker \& Huffington, 2005). There has been an expectation in social work that these reflections would be more authentic and clearly understood. The applications of systemic reflexivity in practice have created greater 
intimacy and a fuller client response in the therapist and client relationship. At the same time, isolating factors like cell phone technology have encouraged separation in social relationships (Przybylski \& Weinstein, 2013). Common barriers to effective empathic exchange have included failure to clarify, inattention, false assumptions, or anticipating the other is using stereotypical screens (Compton, Galaway, \& Cournover, 2005).

Mastering the mechanics of the communication process has been a pivotal point in the conveyance of empathic responding. The ability to integrate and synthesize cues, sense the client, connect one's internal self without getting lost in the other, and then be able to make an advanced empathic response has typically required a special mastery. As with all in-themoment therapies, there needs to be a willing suspension of one's own filters and disbelief (Holland, 2003). The client, or student, has to be willing to let go and trust the therapist.

Integration of more contemporary understanding about introspective empathy has called for broadened perspectives while maintaining an internal locus of control (Kohut, 1978; Wagaman, Geiger, Shockley, \& Segal, 2015). The social worker must have the courage to go with the client in order for the client to fully process and fully receive that interchange (Sinclair \& Monk, 2005). The key to empathy over sympathy is a compassionate connection rather than a feeling of pity or loss of self. The misunderstanding about how to use the reflexive self has led social workers to be affectively restrained and less able to align in full interaction with the client. Such traditional practice philosophies are in dissonance with interactive relationships that should rightfully place the social worker as a collaborative equal with the client.

Sociologists hold a balanced systemic view of empathy and its function. When Keltner, Smith, and Marsh (2010) examined the degree of caring and donation from rich versus poor study participants, an interesting outcome occurred. The Keltner team found both groups possessed the same ability toward a caring temperament. The sociologists posited that being rich or poor was not the causal factor of increased empathy. In order to solicit an empathic response, an individual had to have been exposed to recent acts of altruism. Without that practiced experience, the respondent tended to focus on self-serving and selfinterest stimuli. Therefore, the more people practice or observe empathy, the more empathic they can become (Wagaman et al., 2015).

In the discipline of social work, theorists have wrestled with whether empathy is innate (Buckman, Tulskey, \& Rodin, 2011; Chambers \& Davis, 2012). If empathy theorists have won the argument that empathy is solely genetic, then there would be no reason for social work clinicians to be actively practicing more enlightened empathic approaches. However, there are multiple examples of training modules for empathy and critical thinking development, which have demonstrated efficacy (e.g., Carkuff, 2009; Dearing \& Steadman, 2009; Linker, 2011). With neuroscience discoveries, theorists do now view empathy to be both natural and nurtured.

In order to discern if empathy is present, the easiest manner is through observation of an interpersonal exchange between a sender and a receiver (Jemczura, 2004). Paul (1993) reported that another's empathy experience must be observed to be understood. The observer, therefore, must be fully present to observe and hear the sender. Being fully aware and fully present, the receiver can begin the process of a fair-minded assessment about the 
truths of the sender, through the process of critical thinking. How empathy is felt in the sender/receiver exchange depends on the orientation of the receiver (Blandul, 2015). There is evidence that empathy can be received from a left-brained or right-brained orientation of the receiver. Neuroscience indicates factors like gender may predict whether empathy is processed as an affect function or as a cognitive function, based upon left-brained or rightbrained orientation (Field, 2014). Cognitive empathy presents more prevalently in males; affective empathy presents more prevalently in females (Christov-Moore et al., 2014). In examination of interpersonal exchange, the analysis must look beyond the messages of the sender and receiver to consider awareness, presence, listening, and orientation.

\section{Empathy's Influence on Learning}

According to neuroscientist Immordino-Yang (2016), social emotions shape the way learning occurs. The conductivity across the brain network affects complexity, integration, and social functioning within the world. Thus, a social worker's therapeutic empathy is more complex than simple reflection, acts of altruism, displays of imagination, or the ability to reflect (Sperry, Carlson, \& Kjos, 2002). Therapeutic empathy is respectful of the client's strengths and vulnerabilities and qualitatively adds to the client's verbal and nonverbal messages.

Our socio-cultural environment causes us to feel the implications across the same pathways that keep all human-kind alive - that we are more alike than different from one another. In brain-mapping, observations indicate that feeling alive causes the individual to strive and to share a sense of determination (Parvizi, Rangarajan, Shirer, Desai, \& Greicius 2013). The rational mind must continue to call upon subtle emotional data to assist in the everyday routine of basic decision-making (Lehrer, 2010). There cannot be a splitting or separation over the importance of both thinking and feeling; it is indispensable to have emotion to produce sound reason (Demasio, 1994; LeDoux, 2002).

\section{Emotional Intelligence and its Connection to the Rational Mind}

While the limbic system is the center of our emotional regulation, it continually processes commands from the neocortex, which instructs emotions to activate. However, the limbic emotional regulator is also responsible for our intellectual health. Learning research has indicated the best problem-solvers are those who have the ability to laugh, thus showing a connection between the affective and rational brain (Ruben, 2015.

Neuroscience may hold macro-solutions to global conflicts. An interesting study using a double-blind placebo-controlled within-subject crossover design asked Jewish Israeli participants to report empathy to pain responses for Jewish Israeli participants, Europeans, and then Palestinians (Shamay-Tsoory et al., 2013). The natural experiment revealed that increases in oxytocin resulted in reduction of bias over controls. As a result of the increased oxytocin, the respondents indicated higher levels of empathic connection and compassion for their Palestinian adversaries. Rosenberg (2015) developed a strategy for nonviolence in communication that has also shown success with large diverse populations. Intellectual empathy considers social responsibility to others and has ties to social justice (Dearing \& Steadman, 2009; Linker, 2011). 


\section{A Call for Greater Therapeutic Competency}

A therapist's empathic ability has been considered a fundamental element for recipient change within the therapeutic setting (Elliott, Bohart, Watson, \& Greenberg, 2011; Larson $\&$ Yao, 2005). Core therapist characteristics for optimum empathic response include active listening, good reflective qualities, imagination, risk-taking, altruistic motivation, and the ability to be vulnerable (Eres \& Isen, 2002; Gerdes \& Segal, 2011). Smith (2012) interpreted this as the fundamental ability to intuitively discern how another person would feel in a given situation. The social worker can then use empathy in interpersonal response to convey meaning, feeling, thinking, and content (Compton et al., 2005). Without the proliferation of empathy research, training, definition, and literature, a social worker's empathic ability is still considered only as instinctively understood (Elliott et al., 2011).

In a self-assessment study, undergraduate students reported a need for empathy training in the classroom but also felt discussions from personal experience were a better strategy than only instructor prepared materials (Ruben, 2015; Zaleski et al., 2015). Professors solicited in the same study felt the classroom was exactly the place for expanding personal experiences by adding cultural characteristics that enhanced empathy integration. The initial difficulty for instructors was having all students absorbing the same degree of interpersonal empathy with the same degree of true integrated learning. The professors continued to observe a lack of clear techniques for teaching empathy that achieve good learning outcomes. Ruben (2015) concluded that mixed impressions remain about how to discern empathic properties.

Grant, Kinman, and Baker (2013) conducted a mixed design study to evaluate types of curriculum necessary for social work students experiencing empathic distress. Resiliency training was initiated for undergraduate social work students to address affective sharing and empathic distress. Curriculums included lectures and workshops over a 4-year period, covering mindfulness, stress, irrational beliefs, and reflective supervision to improve practice skills. Savageau (2014) discovered that deliberate training specific to mindfulness by the social worker increased self-compassion and protective resiliency against anxiety, depression, and burnout. Practicing within that empathic proficiency, selfawareness and perspective-taking can be engaged to understand the world of the other (Stanley \& Bhuvaneswari, 2016).

\section{Need for a Consistent Training Protocol}

Despite considerable evidence of empathy's legitimacy, methods for enhancing a therapist's empathic response have not been codified within the literature (Ming Lam, Kolomitro, \& Alamprambil, 2011). Studies offer differing conceptualizations of empathy, combine experimental and non-experimental data, may lack a standardized measurement tool, or are limited to narrative review. The absence of contemporary empirical proofs in training to increase empathic responses and strategies has contributed to decreased reliance upon that skill in favor of diagnosis and psychopathology. Techniques for empathy training need to employ tested approaches (Chambers \& Davis, 2012). Codifying such training techniques would reinforce empathy's potency in the therapeutic world. 


\section{A Training Model}

A selection of a training model might focus on perspective taking, which is amenable to an empathy training model developed by Carkhuff (2009): Human Resource Development training (HRD). Carkhuff was a protégé of Rogers' and sought to take empathy farther into measurability and into response training (Braizer, 1996). In the training process, students are exposed to practice strategies reported to improve empathy for perspective-taking and empathic concern (Chambers \& Davis, 2012; Freedburg \& Vittorio, 2007). The HRD teaching model dissects the interaction between giver and receiver. The outcome of HRD training is to assist the helper/giver to elevate the participant/receiver to respond competently with the highest level of empathic response. HRD training challenges the social worker to be aware of emotion and thought while integrating perspective-taking, empathic concern (compassion), accurate description of distress (another's pain), and fantasy (Chambers \& Davis, 2012; Davis \& Hayes, 2011).

Empathic Origins and Acquisition. Imagination, motivation, and vulnerability have been linked to internal drives, instincts, and aptitudes that inspire individual empathic development (Decety \& Cowell, 2016; Erez \& Isen, 2002; Gerdes \& Segal, 2011). Active listening has often been credited as the competency necessary for the discernment of empathy discrimination - a clinician's discernment of the emotive depth of a client's verbalization. The ability to verbally respond in an empathic manner has been a skill more difficult to achieve than simple discriminatory identification or active listening. These responses have been conveyed as encoded and decoded messages between the sender and the receiver. Encoding and decoding phases have always been vulnerable to distortions and barriers that interfere with the communication process.

Trevithick et al. (2004) challenged that classrooms may not be the appropriate environment for teaching empathic responding. The assumption is that Socratic styles are not compatible with empathy development. To support this, one study observed that physician empathy tended to decrease as the physician became more professionally educated (Dehning et al., 2013). Actual interpersonal exchange benefits were confirmed in a study of weight loss for diabetic patients, and empathy practiced in an actual setting brought better client outcomes (Canale et al., 2012). Social work practitioners similarly achieve more effective client outcomes when they are empathically competent (Gerdes \& Segal, 2011). This competency has been proven achievable in simulated and role-played activities (Chen, Kiersma, Yehle, \& Plake, 2015; Goldstein \& Winner, 2012).

Carkhuff (1984) offered that those without academic training may be better equipped to teach others empathic responding and discrimination because Socratic instructors lacked the necessary flexibility and imagination. However, Carkhuff also proposed that a training instructor needed to be experienced to achieve a certain level of empathic accuracy in order to therapeutically match the client for thought and feeling. Carkhuff's 5-point communication discrimination scale has directed the clinician to be empathically qualified up to two levels beyond a therapeutic reciprocal response (Carkhuff, 1984). The Carkhuff training model has demonstrated significant outcomes in evaluating empathy responses from master's level social work students (VanCleave, 2007). To be qualified for academic and instruction, the trainer would have to be innovative, comprehensive, and theoretically 
grounded (Yochly \& Britto, 2012). Yochly and Britto (2012) supported introduction of novel ways of teaching that went beyond lecture and textbook instruction. Training that promotes insight and skill development is consistent with disciplines such as social work where the mission of the profession is to legitimize therapeutic strategies that promote the flexibility, creativity, and innovation necessary for client growth and development (National Association of Social Workers, 1999).

Empathy and Other Disciplines. Much of what has been written about empathy training and development has come from the fields of medicine, business, and education (Larson \& Yao, 2005). Physicians were found to develop empathy in the presence of role models and experiential opportunities, rather than through Socratic exposure (Marcum, 2013). Further, the use of empathic measures in criminal justice and in court case observations has gained credibility (Crawley \& Suarez, 2016). Unfortunately, laboratory learning of communication skills has not translated well into field practice. As a prosocial skill, empathy promotes open-mindedness, encourages flexibility, promotes creativity and novelty, and discourages rigidity in thought. Studies have affirmed that empathy and learning are intrinsically tied (Leece, Caputi, \& Capnin, 2014). Therefore, introduced as a learning tool, empathy training should be compatible with field placement learning experiences.

Contemporary instruction on nursing ethics recognizes the fundamental necessity to teach empathy and charges that the lack of empathy training is a violation of the nursing ethic for best treatment (McMillian, 2010). A recent study into empathy of the nursing profession revealed that, after a year of professional training, undergraduate nurses showed significant declines in empathy (Ward, Cody, Schaal, \& Hojat, 2015). Social work students have experienced a similar decline within master's programming (Routh, 2005; Wallman, 1980). Scant research has been available on specific social work training in empathic development (Savageau, 2014).

\section{Professional Development}

Research has shown that current education and training programs in social work have not provided the specialized training required in communication and interpersonal relationships. Only anecdotal study has been conducted on the use of psychotherapy to facilitate empathy development (e.g., Jemczura, 2005). Few universities offer full courses on the advancement of clinician empathy. One study asked practicing social workers about learning experiences that forwarded their empathy development beyond the classroom (Savageau, 2014). The top responses included "listening, understanding, natural ability, empathy training, practice, reading about empathy, and spirituality" (pp. 63-64). An expansive training model for clinical empathic response would have to offer a blend of behavioral, cognitive (didactic), and experiential exercises that were cognitively, affectively, and interpersonally blended. This training should be testable to enhance the validity and generalizability of the model (Ming Lam et al., 2011). 


\section{The Importance of Knowing What Aspect of Empathy is being Introduced to Assist in Proper Training Activities.}

Because of the range of therapeutic activities, it is necessary to know what aspects of empathy need to be introduced for what effect. Is the technique to develop trust, fantasy, perspective-taking, distress, concern, or intrinsic identification or to prepare the student for empathic insight and learning (Davis \& Hayes, 2011; Decety, 2010)? The most current studies emphasize internalized empathy, allowing the client/student to feel empathy through systematic exposure and discussion of films. Humor has been tagged with the ability of enhancing empathy and also mediating distress through perspective-change (Hampes, 2016). Research revealed humor through joke-telling had the potential to change perspective through tension reduction and elevation of mood (Niculesu, Van Dijk, Nijholt, Li, \& Lan, 2013). Lachmann (2008) has called the connection between humor, empathy, and creativity transformational.

Transformative learning allows the interaction from the client and therapist to move from the distant to the intimate (Bal \& Veltkamp, 2013; Lachmann, 2008). This is a similar technique to non-dominant hand-writing. The effect is to confuse the brain and open the person to new creativity. Creativity, as displayed in acting and role-play, also enhances empathy (Goldstein \& Winner, 2012). Simulation has been shown to teach empathy (Chen et al., 2015). Additionally, mindfulness techniques have the capacity for elevating empathy awareness (Grant, 2014; Van Lutterveld et al., 2016). Narrative journaling has also been widely utilized for increased perspective-taking (Smith, 2009).

At the macro-level, social work has a natural tendency to align with belief, policies, and opinions that disenfranchise others (Segal \& Wagaman, 2015). Segal supported the benefits of teaching social work students the aspects of social empathy, which presents compassion for broader empathy perspectives and allows for more generalized acceptance of differing political perspectives. Virtual reality has been shown to create compassionate empathy by placing the participant more fully in the scene (Dave, 2015). The study of empathy could be improved by discovering the determinants that make classroom-based exercises progressive and useful. Learning mediums could include role-play, social skill building, emotional connection with another allowing for interpersonal intelligence building, and a sense of community loyalty to foster responsibility, self-control, and cooperation (Briggs, 2014).

\section{Toward a More Empathic Way of Being for the Classroom}

Engagement. Rogers (2003) was so aware of the benefits of his client-centered therapy that he took a similar student-centered approach in the classroom. The supportive therapeutic framework from social work has applicability to the student learning environment (Tenenbaum, 1959). In the classroom, the ability to use multiple teaching approaches provides variety and may include experiential opportunities (Gardner, 2006). The experiential do-think-read application promotes creativity and openness to learning that increases attention and transformation. The scope of this curriculum considers the infusion of these activities within courses throughout the BSW and MSW learning experience. Empathy curriculum should develop in graduated complexity and align with 
other competencies, like the development of critical thinking, analysis of ethical dilemmas, cultural and diversity sensitivity, and professional practice behaviors (Kessen \& Turner, 2012). The instructor needs to be empathically proficient to model and provide activities that teach prosocial behaviors. Faculty will need to practice empathy within their own departments for modeling and continued proficiency.

Assessment of Students' Level of Empathy Competency. Assessing the student's empathy skill readiness would be the first task and consistent with the planned change model and the critical thinking conceptualization (Beaumont, 2010; Dearing \& Steadman, 2009; Kirst-Ashman, 2012). Training modules would need to build from knowledge, to values clarification, and to skill-building as determined by the level of assessed readiness. The knowledge component would consider operationalized empathy definitions and characteristics. The values component would explore characteristics and expanded vocabulary for feelings. Recognition of facial expressions could complete the assessment portion of empathy identification. Implementation of advanced skill-building would follow. Options for empathy training include infusing it into another course, presenting it as a continuing education opportunity, or developing an entire course on empathy.

Implementation/Application of the Plan. Empathy curriculum could be determined after identifying (a) the skill sets to be taught, (b) the number of training hours available, and (c) the applicability of what needs to be learned by a given student. Adjustments can be made to take-home assignments to individualize training. Perspective-taking exercises could include cognitive training, like HRD (Carkhuff, 2009), empathic films, virtual reality videos, storytelling, role-play, labs, simulations, interdisciplinary simulation and advocacy, support/conversation groups, and community service (Jemczura, 2005; Marcum, 2013; Yaniv, 2012). Suspension of disbelief (fantasy) exercises could include laughter, humor, reenactment, imagination, play therapies, and psychodrama (Lachmann, 2008).

The five components of empathy to could be separated into five distinct modules. Empathic Distress could be taught using testimonials, documentaries, affirmation and reduction exercises, music, and singing (Greenberg, Renfrow, \& Baron-Cohen, 2015). Perspective-taking would focus upon interpersonal exchange activities (Yaniv, 2012). Empathy Concern might include oxytocin activation through warm temperatures, touch, and massages. Oxytocin medication is available but is not as effective as non-medical strategies. Empathic Concern can also be produced by encouragement to give monetary donations (Abu-Akel et al., 2014; Barraza \& Zak, 2009; Decety \& Cowell, 2015). Fantasy development could occur in reading fiction, reenactments of fairy tales (Lachmann, 2008 Intrinsic Empathy activities could include activities like yoga, meditation, mindfulness, and reflective journals (Decety, 2010; Grant, 2014). More structured training manuals are available on reliable websites (e.g., Butters, 2010).

Evaluation. The outcomes of empathy competency could be evaluated with the grading system, within practice behavior rubrics, with a pre- and post-class survey, or with tools like those provided by Davis (1980), Carkhuff (2009), or evaluations from structured training manuals. If empathy activities are planned throughout the coursework, there is a greater likelihood that students will incorporate empathy practice into their professional settings. 
Closure. Wrap-up and closure would always be beneficial in module training, as it gives time to reinforce training, complete post assessments, and offer opportunities for student closure, with follow-up recommendations to encourage the student(s) to continue empathy practice. Trainers should consider post-graduation follow-up and refresher workshops to reinforce the training (Ming Lam et al., 2011). Class discussion of post-class synthesis of empathy learning would be a productive use of closure (Beaumont, 2010).

\section{Recommendation}

Empathy has transformational qualities, and there are systematic methods for empathy training. It is recommended that schools of social work infuse empathy training in master of social work courses that incorporate fantasy, empathic concern, perspective-taking, empathic distress, and intrinsic components into curricula. It is important to generate evidence-based outcomes that support empathy as a social work competency.

\section{References}

Abu-Akel, A., Palgi, S., Klein, E., Decety, J., \& Shamay-Tsoory, S. G. (2014). Oxytocin increases empathy to pain when adopting the other-but not the self-perspective. Social Neuroscience. doi:https://doi.org/10.1080/17470919.2014.948637

Aksan, N., \& Kochanska, G. (2005). Conscience in childhood: Old questions, new answers. Developmental Psychology, 41(3), 506-516. doi:https://doi.org/10.1037/0012-1649.41.3.506

Bal, P. M., \& Veltkamp, M. (2013). How does fiction reading influence empathy? An experimental investigation on the role of emotional transportation. PLoS One, 8(1): e55341. Published online. doi:https://doi.org/10.1371/journal.pone.0055341

Barraza, J. A., \& Zak, P. J. (2009). Empathy toward strangers triggers an oxytocin release and subsequent generosity. Annals of New York Academy of Science, 1167(1), 182189. doi:https://doi.org/10.1111/j.1749-6632.2009.04504.x

Beaumont, J. (2010). A sequence of critical thinking tasks. TESOL Journal, 17(13), 1-22. doi:https://doi.org/10.5054/tj.2010.234763

Blandul, V. C. (2015). The role and status of didactic communication in education activity. Procedia-Social and Behavioral Sciences, 191, 2568-2572. doi:https://doi.org/10.1016/j.sbspro.2015.04.584

Braizer, D. (1996). The post-Rogerian therapy of Robert Carkhuff. Amida Trust. Retrieved from http://www.academia.edu/3663201/The_PostRogerian_Therapy_of_Robert_Carkhuff

Briggs, S. (2014). How empathy affects learning and how to cultivate it in your students. Retrieved from http://www.opencolleges.edu.au/informed/features/empathy-andlearning/

Buckman, R., Tulskey, J. A., \& Rodin, G. (2011). Empathic responses in clinical practice: Intuition or tuition? Canadian Medical Association Journal, 183(5), 569571. doi:https://doi.org/10.1503/cmaj.090113 
Butters, R. P. (2010). A meta-analysis of empathy training programs for client populations (Doctoral dissertation, The University of Utah). Retrieved from https://collections.lib.utah.edu/details?id=192380

Canale, D., Louis, D. Z., Maio, V., Wang, X., Rossi, G., Hojat, M., \& Gonnella, J. S. (2012). The relationship between physician empathy and disease complications: An empirical study of primary care physicians and their diabetic patients in Parma, Italy. Academic Medicine, 87(9), 1243-1249. doi:https://doi.org/10.1097/ACM.0b013e3182628fbf

Carkhuff, R. R. (1984). Helping and human relations. Amherst, MA: Human Relationship Development Resource (HRD) press. (originally published in 1969).

Carkhuff, R. R. (2009). The art of helping. Amherst, MA: HRD Press.

Chambers, J. R., \& Davis, M. H. (2012). The role of the self in perspective-taking and empathy. Social Cognition, 30, 153-180. doi:https://doi.org/10.1521/soco.2012.30.2.153

Chen, A., Kiersma, M. E., Yehle, K. S., \& Plake, K. S. (2015). Impact of an aging simulation game on pharmacy students' empathy for older adults. American Journal of Pharmaceutical Education, 79(5), 1-5. doi: https://doi.org/10.5688/ajpe79565

Christov-Moore, L., Simpson, E. A., Coude, G., Grigaityte, K., Iacoboni, M., \& Ferrari, P. F. (2014). Empathy: Gender effects in brain and behavior. Neuroscience \& Biobehavioral Reviews, (46)4, 604-627. doi:https://doi.org/10.1016/j.neubiorev.2014.09.001

Cialdini, R. B., Schaller, M., Houlihan, D., \& Beaman, A. (1991). Altruism or egoism? That is (still) the question. Psychological Inquiry, 2(2), 124-126. doi:https://doi.org/10.1207/s15327965pli0202_3

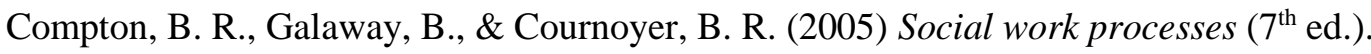
Belmont, CA: Brooks/Cole.

Crawley, D., \& Suarez, R. (2016). Empathy, social dominance orientation, morality salience, and perceptions of criminal defendant. Sage Journals. Retrieved from: http://journals.sagepub.com/doi/full/10.1177/215824401662918

Dave, S. (2015). Simulation in psychiatric teaching. Advances in Psychiatric Treatment, 18, 292-298. doi:https://doi.org/10.1192/apt.bp.110.008482

Davis, M. H. (1980). A multidimensional approach to individual differences in empathy. Catalog of Selected Documents in Psychology, 10, 85. Retrieved from http://www.ucp.pt/site/resources/documents/ICS/GNC/ArtigosGNC/AlexandreCastro Caldas/24_Da80.pdf

Davis, D. M., \& Hayes, J. A. (2011). What are the benefits of mindfulness? A practice review of psychotherapy-related research. Psychotherapy, 489(2), 198-208. Retrieved from https://www.apa.org/pubs/journals/features/pst-48-2-198.pdf 
Dearing, K. S., \& Steadman, S. (2009). Enhancing intellectual empathy: The lived experience of voice simulation. Perspectives in Psychiatric Care, 45(3), 173-182. doi:https://doi.org/10.1111/j.1744-6163.2009.00219.x

Decety, J. (2010). The neurodevelopment of empathy in humans. Development Neuroscience, 32(4), 257-267. doi:https://doi.org/10.1159/000317771

Decety, J., \& Cowell, J. M. (2016). Empathy, justice, and moral behavior. American Journal of Behavioral Neuroscience, 6(3), 3-14. doi:https://doi.org/10.1080/21507740.2015.1047055

Decety, J., \& Svetlova, M. (2012). Putting together phylogenetic and ontogenetic perspectives on empathy. Developmental Cognitive Neuroscience, 2, 1-24. doi:http://dx.doi.org/10.1016/j.den.2011.05.003

DeCruz, H., Boudry, M. DeSmedt, J., \& Blancke, S. (2011). Evolutionary approaches to epistemic justification. Dialectia, 65(4), 517-538. doi:https://doi.org/10.1111/j.1746$\underline{\text { 8361.2011.01283.x }}$

Dehning, S., Gasperi, S., Krase, D., Meyer, S., Reiss, E., Burger M.,... Siebeck, M. (2013). Emotional and cognitive empathy in first-year medical students. Psychiatry, online. doi:http://dx.doi.org/10.1155/2013/801530

Demasio, A. R. (1994). Decartes' error: Emotion, reason, and the human brain. New York, NY: Harper.

Dvash, J., \& Shamay-Tsoory, S. G. (2014). Theory of mind and empathy as multidimensional constructs: Neurological foundations. Topics in Language Disorders, 34(4), 285-292. doi:https://doi.org/10.1097/TLD.0000000000000040

Elliott, R., Bohart, A. C., Watson, J. C., \& Greenberg, L. S. (2011). Empathy. Psychotherapy, 48, 43-49. doi:https://doi.org/10.1037/a0022187

Eres, R., Decety, J., Louis, W. R., \& Molenberghs, P. (2015). Individual differences in local gray matter density are associated with differences in affective and cognitive empathy. NeuroImage, 117, 305-315. doi:https://doi.org/10.1016/j.neuroimage.2015.05.038

Erez, A., \& Isen, A. M. (2002). The influence of positive affect on the components of expectancy motivation. Journal of Applied Psychology, 87(6), 1055-1067. doi:http://dx.doi.org/10.1037/0021-9010.87.6.1055

Field, T. A. (2014). Integrating left-brain and right-brain: The neuroscience of effective counseling. The Professional Counselor, 4(1), 19-27. doi:https://doi.org/10.15241/taf.4.1.19

Freedburg, D., \& Vittorio, G. (2007). Motion, emotion and empathy in aesthetic experience. Trends in Cognitive Sciences, 11(5), 197-203. doi:http://dx.doi.org/10.1016/j.tics.2007.02.003

Gardner, H. (2006). Multiple intelligences: New horizons. New York, NY: Basic Books. 
Gendlin, E. T. (1962). Experiencing and the creation of meaning. New York, NY: Free Press.

Gerdes, K. E., \& Segal, E A. (2011). Importance of empathy for social work practice: Integrating new science. Social Work, 56(2), 141-148. doi:https://doi.org/10.1093/sw/56.2.141

Gerdes, K. E., Segal, E. A., Jackson, F. K., \& Mullens, J. L. (2011). Teaching empathy: A framework rooted in social cognitive neuroscience and social justice. Journal of Social Work Education, 47(1). Retrieved from http://www.freepatentsonline.com/article/Journal-Social-WorkEducation/253625665.html

Gerdes, K. E., Segal, E. A., \& Lietz, C. A. (2010). Conceptualising and measuring empathy. British Journal of Social Work, 40(7), 2326-2343. doi:https://doi.org/10.1093/bjsw/bcq048

Goldstein, E. R., \& Winner, E. (2012). Enhancing empathy and the theory of mind. Journal of Cognition and Development, 13(1), 19-37. doi:https://doi.org/10.1080/15248372.2011.573514

Grant, L. (2014). Hearts and minds: Aspects of empathy and well-being in social work students. Social Work Education, 33(3), 338-352. doi:http://dx.doi.org/10.1080/02615479.2013.805191

Grant, L., Kinman, G., \& Baker, S. (2013). Developing an "emotional curriculum" for social workers: Perceptions of social work lecturers. The Higher Education Academy research report. Retrieved from https://www.heacademy.ac.uk/system/files/hsc14developinng-an-emotional-curriculum 1.pdf

Greenberg, D. M., Rentfrow, P. J., \& Baron-Cohen, S. (2015). Can music increase empathy? Interpreting musical experience through the empathizing-systemizing (E-S) theory: Implications for autism. Empirical Musicology Review, 10(1), 79-94. doi:https://doi.org/10.18061/emr.v10i1-2.4603

Gu, X., Hof, P. R., Friston, K. J., \& Fan, J. (2013). Anterior insular cortex and emotional awareness. Journal of Comprehensive Neurology, 521(15), 3371-3388. doi:https://doi.org/10.1002/cne.23368

Hampes, W. (2016). The relationship between humor styles and forgiveness. Europe's Journal of Psychology, 12(3), 338-347. doi:https://doi.org/10.5964/ejop.v12i3.1012

Hieker, C., \& Huffington, C. (2005). Reflexive questions in a coaching psychology context. International Coaching Psychology Review, 1(2), 47-56. Retrieved from http://www.hilcoaching.com/pdf/HiekerHuffington.pdf

Holland, N. N. (2003). The willing suspension of disbelief: A neuro-psychoanalyical view. PsOnline Journal for Psychological Study of the Arts, 2(6). Retrieved from: http://psyartjournal.com/article/show/n hollandthe_willing_suspension_of_disbelief_a_ne 
Immordino-Yang, M. H. (2016). Emotions, learning, and the brain: Exploring the educational implications of affective neuroscience. New York, NY: W. W. Norton.

Jemczura, T. (2004). Empathy as a form of interpersonal communication. Pedagogika, 75, 22-27. Retrieved from www.biblioteka.vpu.lt/pedagogika/PDF/2005/75/jemczura.pdf

Juliusdottir, S. (2006). The emerging paradigm shift in social work in the context of current reforms of European social work education. Social Work International Society Online Journal, 4(1). Retrieved from http://www.socwork.net/sws/article/view/175/566

Kasapi, Z., \& Mihiotis, A. (2014). Emotional intelligence quotient and leadership effectiveness in the pharmaceutical industry: A new template. International Journal of Business Administration, 5(1), 15-26. doi:http://dx.doi.org/10.5430/ijba.v5n1p15

Keltner, D., Smith J. A., \& Marsh, J. (Eds.). (2010). The compassionate instinct: The science of human goodness. New York, NY: W. W. Norton.

Kessen, C., \& Turner, K. (2012). Developing professional confidence in graduate school: Student experiences of social work curriculum, Public Voices, 12(2), 10-18.

Kirst-Ashman, K. (2012). Introduction to social work \& social welfare: Critical thinking perspective. Boston, M.A.: Brooks/Cole.

Kohut, H. (1978). Introspection, empathy, and psychoanalysis: An examination of the relationship between mode of observation and theory. In P. Ornstein (Ed.), The search for the self, (vol. 1, pp. 205-232). New York, NY: International Universities Press.

Lachmann, F. M. (2008). Transforming narcissism: Reflections from empathy, humor, and expectations. New York, NY: Routledge.

Larson, E., \& Yao, X. (2005). Clinical empathy as emotional labor in the patientphysician relationship, Journal of the American Medical Association, 293(9), 11001106. doi:https://doi.org/10.1001/jama.293.9.1100

LeDoux, J. (2002). Synaptic self: How our brains become who we are. New York, NY: Viking.

Leece, S., Caputi, M., \& Capnin A. (2014). Long-term effect of theory of mind on school achievement: The role of sensitivity to criticism. European Journal of Developmental Psychology, 11(3), 305-318. doi:https://doi.org/10.1080/17405629.2013.821944

Lehrer, J. (2010). How we decide. Boston, MA: Houghton Mifflin.

Linker, M. (2011). Do squirrels eat hamburgers? Intellectual empathy as a remedy for residual prejudice. Informal Logic, 31(2), 110-138. Retrieved from http://www.academia.edu/2333046/Do_Squirrels_Eat_Hamburgers_Intellectual_Emp athy as a Remedy for Residual Prejudice 
Loyola, M. L. (2016). Demographic profile and empathy level of helping professionals. Asia Pacific Journal of Multidisciplinary Research, 4(3), 26-33.

Marcum, J. A. (2013). The role of empathy and wisdom in medical practice and pedagogy: Confronting the hidden curriculum. Journal of Biomedical Education, 2013, 1-8. doi:https://doi.org/10.1155/2013/923810

Martin, L. J., Hathaway, G., Isbester K., Mirali, S., Acland E. L., Niederstrasser,...\& Trost, S. (2015). Reducing social stress elicits emotional contagion of pain in mouse and human strangers. Current Biology, 25(3), 326-332. doi: https://doi.org/10.1016/j.cub.2014.11.028

Mathias, J. (2015). Thinking like a social worker: Examining the mean of critical thinking in social work. Journal of Social Work Education, 51(3), 457-474. Retrieved from http://www.tandfonline.com/doi/pdf/10.1080/10437797.2015.1043196?needAccess=t $\underline{\text { rue }}$

McMillian, R. L. (2010). Teaching nursing students empathic communication: A mandate from the code of ethics for nursing. Online Journal of Health Ethics, 6(1), Article 7. doi: http://dx.doi.org/10.18785/ojhe.0601.07

Miehls, D., \& Moffatt, K. (2000). Constructing social work identity based on the reflexive self. British Association of Social Workers, 30(3), 339-348. doi:https://doi.org/10.1093/bjsw/30.3.339

Ming Lam, T.C., Kolomitro, K., \& Alamprambil, F. C. (2011). Empathy training: Methods, practice, evaluation, and validity. Journal of Multidisciplinary Evaluation, 7(16), 162-200. Retrieved from http://journals.sfu.ca/jmde/index.php/jmde_1/article/viewFile/314/327

Morelli, S. A., Leiberman, M. D., \& Zaki, A. (2015). The emerging study of positive empathy. Social \& Personality Psychology Compass, 9(2), 57-68. doi:https://doi.org/10.1111/spc3.12157

Mutschler, I., Reinbold, C., Wankerl, J., Seifritz, E., \& Ball, T. (2013). Structural basis of empathy and the general domain region in the anterior insular cortex. Neuroscience, 7, 177-183. doi:https://doi.org/10.3389/fnhum.2013.00177

National Association of Social Workers. (1999). Code of ethics of the National Association of Social Workers. Washington D. C.: Author.

Niculesu, A., Van Dijk, B., Nijholt, A., Li, H., Lan, S. S. (2013). Making social robots more attractive: The effects of voice pitc, humor and empathy. International Journal of Social Robotics, 5(2), 171-191. doi:https://doi.org/10.1007/s12369-012-0171-x

Nilsson, P. (2014). Are empathy and compassion bad for the professional social worker? Advances in Social Work, 15(2), 294-305. Retrieved from https://journals.iupui.edu/index.php/advancesinsocialwork/article/viewFile/17679/18 $\underline{385}$ 
Norcross, G. (2011). Psychotherapy relationships that work: Evidence-based responsiveness ( $2^{\text {nd }}$ ed.). New York, NY: Oxford University Press. doi:https://doi.org/10.1093/acprof:oso/9780199737208.001.0001

Ong, D. C., Zaki, J., \& Goodman, D. (2015). Affective cognition: Exploring lay theories of emotion. Cognition, 143, 141-162. doi:http://dx.doi.org/10.1016/j.cognition.2015.06.010

Parvizi, J., Rangarajan, V., Shirer, W. R., Desai, N., \& Greicius, M. D. (2013). The will to persevere induced by electrical stimulation of the human cingulate gyrus. Neuron, 80(6), 1359-1367. doi:http://dx.doi.org/10.1016/j.neuron.2013.10.057

Paul, R. (1993). Critical thinking, moral, integrity, and citizenship. The Critical Thinking Community. Retrieved from http://www.criticalthinking.org

Pavey, L., Greitemeyer, T., \& Sparks, P. (2012). I want to help not because you tell me to: Empathy increased anonymously motivated helping. Personality and Social Psychology Bulletin, 38(5), 681-689. doi:https://doi.org/10.1177/0146167211435940

Przybylski, A., \& Weinstein, N. (2013). Can you connect with me now? How the presence of mobile communication technology influences face-to-face conversation quality. Journal of Social and Personal Relationships, 30(3), 237-246. doi:https://doi.org/10.1177/0265407512453827

Rogers, C. R. (1975). The unanticipated way of being. The Counseling Psychologist, 5(2), 2-10. Retrieved from http://www.sageofasheville.com/pub downloads/EMPATHIC AN UNAPPRECIATED WAY OF BEING.pdf doi:https://doi.org/10.1177/001100007500500202

Rogers, C. R. (2003). Client-centered therapy: Its current practice, implications, and theory. London, England: Constable Press. (Original work published in 1951)

Rosenberg, M. B. (2015). Nonviolent communication: A language of life $\left(3^{\text {rd }}\right)$. Encinitas, CA: PuddleDancer Press.

Routh, M. R. (2005). Empathy and the MSSW curriculum: Are students' levels of empathy influenced by the curriculum? Master's Thesis, University of Tennessee, 2005. Retrieved from http://trace.tennessee.edu/utk_gradthes/2284.

Ruben, J. (2015). Can social work students learn empathy? Social Work Today, 15(2), Retrieved from https://www.linkedin.com/pulse/can-social-work-students-learnempathy-victoria-baker

Savageau, S. (2014). Focused practice: Exploring the relationship between mindfulness and empathy among clinical social workers. Master of Social Work Clinical Research Papers. Paper 258. Retrieved from http://sophia.stkate.edu/msw papers/258

Segal, E. A., \& Wagaman, M. A. (2015, January). Social empathy as a framework to infuse competency in advancement of social and economic justice in social work education. Presented at the Society for Social Work and Research (SSWR) The 
Society for Social and Behavioral Importance of Increased Longevity Conference, New Orleans, LA.

Shamay-Tsoory, S. G. (2015). The neuropsychology of empathy: Evidence from lesion studies. Revue De Neuropsychologie, 4(7), 1-17. Retrieved from https://www.cairn.info/revue-de-neuropsychologie-2015-4-page-237.htm

Shamay-Tsoory S. G., Abu-Akel A, Palgi S., Sulieman R., Fischer-Shofty M., Levkovitz Y., \& Decety J. (2013). Giving peace a chance: Oxytocin increases empathy to pain in the context of the Israeli-Palestinian conflict. Psychoneuro-endocrinology, 38(12), 3139-3144. doi:https://doi.org/10.1016/j.psyneuen.2013.09.015

Sinclair, S. L., \& Monk, G. (2005). Discursive empathy: A new foundation for therapeutic practice. British Journal of Guidance and Counseling, 33, 333-349. doi:https://doi.org/10.1080/03069880500179517

Smith, H. (2012). The spaces in-between: How the art of intuition informs the science of evidence-based practice in psychotherapy. Master of Social Work Clinical Research Papers. Paper 93. Retrieved from http://sophia.stkate.edu/msw papers/93

Smith, J. (2009). Emotional intelligence and professional education: The use of narrative journaling. The International Journal of Learning, 16(7), 81-92. doi:https://doi.org/10.18848/1447-9494/cgp/v16i07/46458

Sperry, L., Carlson, J., \& Kjos, D. (2002). Becoming an effective therapist. Boston, MA: Allyn \& Bacon.

Spinrad, T. L., \& Stifter, C. A. (2006). Toddler's empathy related to responding to distress: Prediction from negative emotionality and maternal behavior in infancy. Infancy, 10(2), 97-121. Retrieved from http://hhd.psu.edu/ebp/documents/SpinradStifter2006.pdf doi:https://doi.org/10.1207/s15327078in1002_1

Stanley, S., \& Bhuvaneswari, G. M. (2016). Reflective ability, empathy, and emotional intelligence in undergraduate social work students: A cross-sectional study from India. Social Work Education, 35(5), 560-575. doi:https://doi.org/10.1080/02615479.2016.1172563

Tenenbaum, S. (1959). Carl R. Rogers and non-directive teaching. Retrieved from http://www.ascd.org/ASCD/pdf/journals/ed_lead/el_195902_tenenbaum.pdf

Trevithick, P., Richards, S., Ruch, G., Moss, B., Lines, L., \& Manor, O. (2004). Teaching and learning communication skills in social work education, SCIE Knowledge Review, 6, Bristol, UK: Policy Press.

VanCleave, D. S. (2007). Empathy training for master's level social work students facilitating advanced empathy responding (Doctoral dissertation). Retrieved from ProQuest (3278305)

Van Lutterveld, R., Houlihan, S. D., Pal, P., Sacchet, M. D., McFarlane-Blake, C., Patel, P. R.,... Brewer, J. A. (2016). Source-space EEG neurofeedback links subjective 
experience with brain activity during effortless awareness meditation. NeuroImage. Advance online publication. doi:https://doi.org/10.1016/j.neuroimage.2016.02.047

Wagaman, M. A., Geiger, J. M., Shockley, C., \& Segal, E. A. (2015). The role of empathy in burnout, compassion, satisfaction and secondary traumatic stress among social workers. Social Work, 60(3), 201-209. doi:https://doi.org/10.1093/sw/swv014

Ward, J., Cody, J., Schaal, M., \& Hojat, M. (2015). The empathy enigma: An empirical study of decline in empathy among undergraduate nursing students. Journal of Professional Nursing, 28(1), 34-40. doi:http://dx.doi.org/10.1016/j.profnurs.2011.10.007

Wallman, G. U. (1980). Impact of the first year social work education on students' skills in communicating empathy and discrimination of effect responses. (Doctoral Dissertation Adelphia University School of Social Work, 1980). Dissertation Abstracts International, 41(05) 2299A. UMI No. 802406.

Welp, L. R., \& Brown, C. M. (2013). Self-compassion, empathy, and helping intentions. The Journal of Positive Psychology, 9, 54-65. doi:https://doi.org/10.1080/17439760.2013.831465

Yaniv, D. (2012). Dynamics and creativity of empathy in role reversal: Contributions from neuroscience. Review of General Psychology, 16(1), 70-77. doi:http://dx.doi.org/10.1037/a0026580

Yochly, A., \& Britto, L. R. G. (2012). Novelty, but not operant adverse learning, enhances Fos and Egr-1 expression in the medial prefrontal cortex and hippocampal areas of rats. Behavioral Neuroscience, 126(6), 826-834. doi:https://doi.org/10.1037/a0030721

Zaleski, K., Araque, J., Sela-Amit, M., Finney, K., Harper, H., \& Lewis, J. (2015). USC study feels out empathy in students, by S. Shin, USCNews. Retrieved from https://news.usc.edu/82898/usc-study-feels-out-empathy-in-students/

\section{Author note:}

Address correspondence to: Diane S. VanCleave, Department of Social Work, Indiana State University, Room 421, 749 Chestnut Street, Terre Haute, IN 47809, 812-237-3388, Diane.VanCleave@indstate.edu 